\title{
Dosador mecânico de precisão para sementes miúdas: Testes funcionais
}

\author{
$\overline{\text { Ângelo V. dos Reis }{ }^{1} \& \text { Fernando A. Forcellini² }}$
}

\begin{abstract}
RESU MO
Com a tecnologia atual, há uma limitação na quantidade mínima de sementes miúdas (trigo, arroz, aveia, colza) que pode ser distribuída em uma área, e com isto, um obstáculo à redução dos custos de produção; assim, o desenvolvimento de mecanismos dosadores de precisão para culturas de sementes miúdas já se iniciou. 0 presente trabalho tem 0 objetivo de apresentar os resultados obtidos durante os testes de um protótipo de dosador mecânico tipo cilindro vertical de dupla face, no que se refere ao seu desempenho funcional na dosagem e deposição de sementes de arroz. Foram avaliadas, em laboratório, a porcentagem de enchimentos de células, a regularidade de distribuição longitudinal de sementes e a danificação mecânica de sementes. Conclui-se que a porcentagem de enchimento de células variou de 103,5 a 113,3\% nas mel hores condições de operação; que a acurácia de dosagem alcançada na saída do tubo condutor, expressa através dos tempos aceitáveis, foi de 34,5\%; que tanto o nível de sementes no reservatório quanto a inclinação lateral do dosador não afetaram, de forma significativa, a acurácia e enfim, que o protótipo causou danificação mecânica às sementes de arroz, da ordem de $3,5 \%$.
\end{abstract}

Palavras-chave: dosador de sementes, semeadura de arroz, cilindro vertical

\section{Precision mechanical seed meter for small seeds: Functional tests}

\begin{abstract}
With current technology there is a limit to the minimum amount of small seeds (wheat, rice, oats, rape seed) that can be distributed in an area which is an obstacle in reducing production costs. Therefore, the development of precision seed meters for small grain crops has already begun. This paper presents the results obtained during the tests of the prototype of a seed meter consisting of a vertical double-face mechanical cylinder, concerning its functional performance in metering and placing rice seeds. Laboratory tests were made to access the percentage of cell fill, the regularity of longitudinal distribution of seeds and the mechanical injury to the seeds. The conclusions were: the percentage of cell fill ranged from 103.5 to $113.3 \%$ in the best operational conditions; the seed metering accuracy reached at outlet of the seed tube, expressed as acceptable time, was $34.5 \%$; both the level of seeds in the hopper and the lateral inclination of the seed meter did not statistically affect the accuracy and, finally, the prototype caused mechanical injuries to of the seeds of the order of $3.5 \%$.
\end{abstract}

Key words: seed meter, rice sowing, vertical cylinder

\footnotetext{
1 DER/UFPEL, CP 354, CEP 96010-900, Pelotas, RS. Fone: (53) 3275-7126; fax: (53) 3275-9031. E-mail: areis@ufpel.tche.br

2 EM C/UFSC, CP 476, CEP 88040-900, Florianópolis, SC. Fone/fax: (48) 3331-7063. E-mail: forcellini@deps.ufsc.br
} 


\section{INTRODUÇÃO}

A elevação do custo das sementes ditas miúdas (trigo, arroz, aveia, colza) torna necessário o desenvolvimento de semeadoras que tenham um controle mais efetivo sobre a população de plantas, o que pode ser conseguido com a utilização de semeadoras de precisão. Essas máquinas possuem mecanismos dosadores que permitem a colocação de sementes espaçadas umas das outras, dentro da linha de semeadura, com distâncias definidas gerando, assim, um potencial para a redução da quantidade de sementes utilizadas por hectare.

Uma análise do mercado nacional de semeadoras (Reis \& Forcellini, 2002) evidencia a ausência de semeadoras de precisão destinadas às sementes dos cereais mencionados; isto se deve tanto à dificuldade de individualizar e transportar sementes de tamanho reduzido e de formas irregulares como ao fato dessas culturas serem semeadas com pequenos espaçamentos entre linhas, requerendo mecanismos dosadores pequenos e estreitos, características essas ausentes nos mecanismos dosadores de precisão atualmente empregados. Fica claro, portanto, que com a tecnologia atual há uma limitação na quantidade mínima de sementes que pode ser utilizada em uma área e, com isto, um obstáculo à redução dos custos de produção, principalmente quando se considera o custo elevado das sementes de qualidade.

O desenvolvimento de mecanismos dosadores de precisão para culturas de sementes miúdas já se iniciou no Brasil. Casão Junior (1996) desenvolveu um mecanismo dosador pneumático com concepção distinta daquelas observadas em semeadoras comerciais com o intuito de possibilitar não apenas a semeadura de precisão mas também a de fluxo contínuo, com transporte pneumático das sementes. $\mathrm{O}$ mecanismo é constituído de um rotor vertical dosador funcionando com sucção de ar. O sistema apresentou resultados satisfatórios quanto à distribuição longitudinal de sementes de milho, soja e trigo, com $78,3,88,4$ e $58,4 \%$ de espaçamentos aceitáveis, respectivamente. O nível de pressão de sucção e a velocidade do rotor tiveram influência significativa nos resultados. $\mathrm{O}$ autor recomenda o aprofundamento dos estudos quanto ao transporte pneumático das sementes, do dosador até o solo.

Seguindo uma linha diferente, Butierres (2003) utilizou um mecanismo dosador de disco vertical a vácuo comercialmente disponível para a dosagem de sementes de arroz; segundo ele, os resultados foram satisfatórios (densidade de semeadura de 73 sementes por metro para uma meta de 64) com discos de 36 orifícios de 1,6 mm de diâmetro; no entanto, o dosador, originalmente projetado para trabalhar com sementes graúdas, teria limitações para semear culturas como o arroz irrigado, que utilizam espaçamento entre linhas de $0,17 \mathrm{~m}$ (menor que a própria largura do dosador utilizado).

Segundo Casão Júnior (1996) os parâmetros de desempenho a serem analisados nos ensaios de semeadoras de precisão previstos nas normas brasileiras se referem à regularidade de distribuição transversal e longitudinal de sementes e danificação causada às sementes no processo de dosagem. Desses, a regularidade de distribuição longitudinal de semen- tes é aquela que define a acurácia do mecanismo dosador de sementes, mas, conforme Kachmann \& Smith (1995), a especificação completa da distribuição dos espaçamentos entre plantas requer a definição e o emprego de um número de parâmetros, pois apenas uma medida, por si só, não seria adequada para comparar mecanismos dosadores. De acordo com esses autores, os parâmetros empregados para a avaliação da regularidade de distribuição de sementes são: a média, o desvio padrão e as medidas relativas a um espaçamento de referência.

Os espaçamentos de referência normalmente empregados são os espaçamentos aceitáveis, falhas, múltiplos. A ABNT (1994) define como distância entre sementes, a distância entre sementes, ou grupo de sementes, em uma mesma linha de semeadura, medida a partir do centro geométrico de sementes consecutivas. Distância referência (Xref) é a distância entre sementes, definida a partir da recomendação agronômica de densidade de semeadura; aceitáveis, referemse ao termo que caracteriza a ocorrência de distâncias entre sementes de 0,5 a 1,5 Xref; múltiplos, dizem respeito ao termo que caracteriza a ocorrência de distâncias entre sementes menores que 0,5 Xref; falhas, referem-se ao termo que caracteriza a ocorrência de distâncias entre sementes maiores que 1,5 Xref.

A porcentagem de enchimento de células, embora não seja padronizada por normas, também é empregada para verificar a acurácia de mecanismos dosadores; é definida como a razão entre o número total de sementes dosadas e o número de células que passaram sobre o tubo condutor; este valor indica a qualidade de funcionamento do mecanismo com relação à acurácia na dosagem. Deve-se ter cuidado, entretanto, com a sua interpretação, pois um valor de $100 \%$ pode não significar que todas as células que passaram sobre o orifício de saída tinham uma semente, pois pode haver a dosagem de múltiplas sementes e, também, falhas na dosagem (células vazias) de forma a compensar o valor obtido (Fey et al., 1999).

Tendo em vista a escassez de informações a respeito da semeadura de precisão de sementes miúdas objetivou-se, no presente trabalho, apresentar os resultados obtidos durante os testes de um protótipo de dosador de sementes miúdas no que se refere ao seu desempenho funcional na dosagem e deposição de sementes de arroz.

\section{MATERIAL E MÉTODOS}

O mecanismo dosador ensaiado apresenta um cilindro vertical estreito, com duas faces operativas, onde se encontram as células de dosagem, com formato alongado, tendo o seu início na superfície plana das extremidades laterais deste disco e o final em superfícies inclinadas em cada uma das faces, para facilitar a retenção das sementes dosadas. A exclusão das sementes excedentes em cada célula, assim como a retenção e o transporte das sementes dosadas até o ponto de ejeção, são auxiliados por um par de escovas laterais externas que recobrem cada uma das faces operativas do cilindro dosador, desde a câmara de dosagem até o 
ponto de ejeção das sementes junto ao tubo condutor. $\mathrm{O}$ cilindro vertical é posicionado entre o reservatório de sementes e o solo, de forma que o plano vertical perpendicular ao eixo do disco formado seja paralelo à direção de deslocamento da máquina semeadora ocupando, assim, pouco espaço. Apresenta-se, na Figura 1, um esquema em três dimensões do protótipo montado.

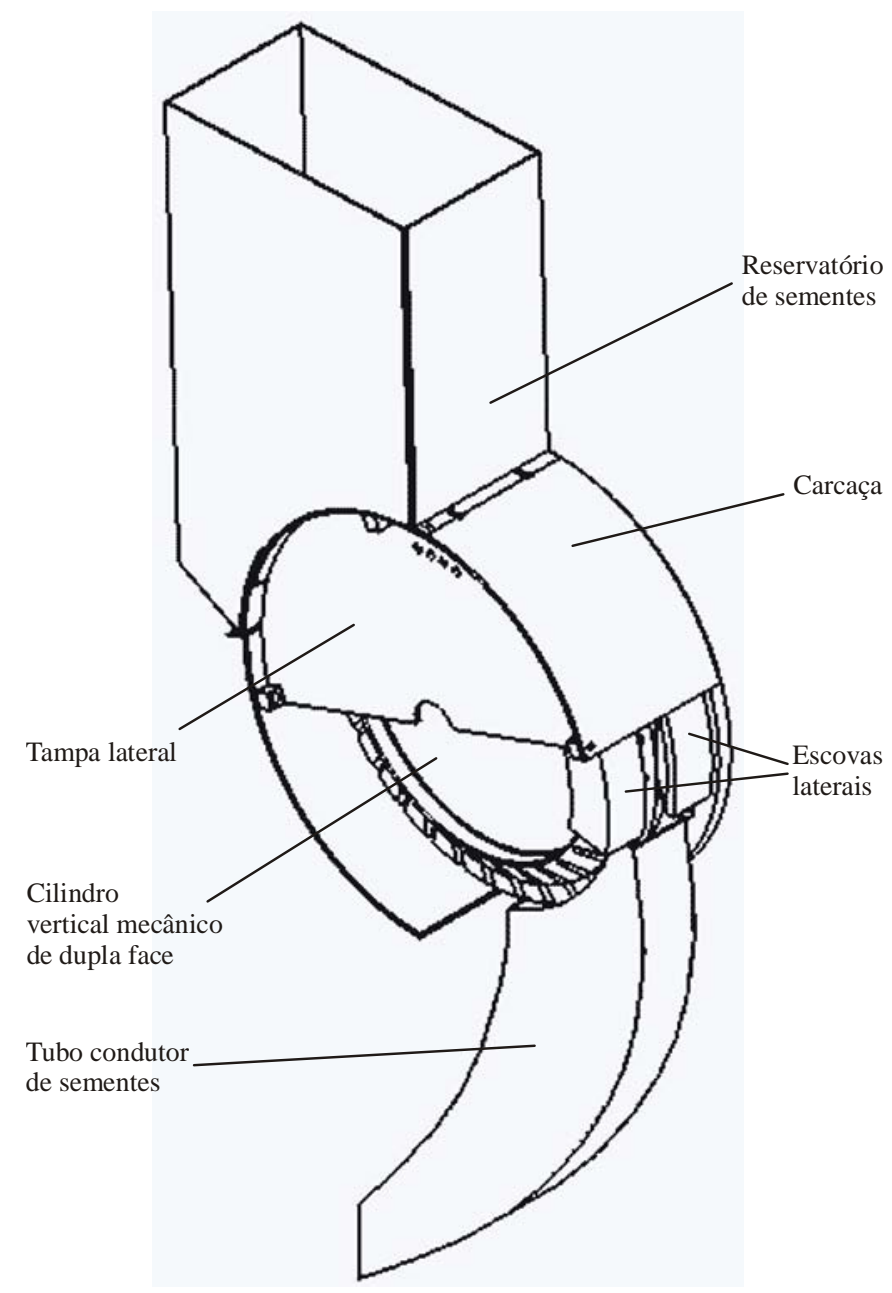

Figura 1. Vista geral em três dimensões do mecanismo dosador.

A efetividade do cilindro mecânico na dosagem de sementes foi avaliada através de um experimento, durante o qual foi contado o número de sementes dosadas correspondendo à passagem de 256 células sobre o local de ejeção. A relação percentual entre o número de sementes dosadas e o número de células corresponde à porcentagem de enchimento de células. As variáveis independentes estudadas foram a velocidade tangencial das células e a posição da escova de retenção lateral, em relação ao fundo da câmara de dosagem.

A velocidade tangencial dos orifícios foi variada em três níveis $\left(0,10,0,22\right.$ e $0,30 \mathrm{~m} \mathrm{~s}^{-1}$, correspondendo a rotações de 8,$8 ; 18,6$ e $25,8 \mathrm{rpm}$, respectivamente) através da alteração da rotação do motor de passo da bancada de teste. A posição das escovas foi ajustada nos valores extremos: com a ponta a $29,0 \mathrm{~mm}$ do fundo da câmara de dosagem (posição 1) e com a ponta a $65,0 \mathrm{~mm}$ (posição 2). O delineamento experimental adotado foi o fatorial $3 \times 2$, que gera seis tratamentos, para os quais foram feitas quatro repetições. A contagem das sementes foi manual, a partir das amostras recolhidas na saída do tubo condutor para cada uma das repetições dos tratamentos.

Para verificar a acurácia do protótipo, determinou-se a regularidade de distribuição longitudinal de sementes, quando eram variados a inclinação lateral do conjunto, a velocidade tangencial das células e o nível de sementes no reservatório. A velocidade tangencial das células foi variada em dois níveis: $0,10 \mathrm{~m} \mathrm{~s}^{-1}$ (V1) e $0,25 \mathrm{~m} \mathrm{~s}^{-1}$ (V2), correspondendo a rotações no cilindro de 8,8 e $21,5 \mathrm{rpm}$, respectivamente, e a inclinação lateral foi variada em dois níveis: $0^{\circ}$ (I0) e $11^{\circ}$ (I1), conforme preconiza a ABNT (1994) para ensaios de laboratório de mecanismos dosadores. O nível de sementes no reservatório foi variado, também, em dois níveis: $25 \%$ da capacidade (N1) e 50\% da capacidade (N2).

$\mathrm{O}$ delineamento experimental adotado para avaliar o efeito das variáveis apresentadas na regularidade de distribuição longitudinal de sementes, foi o fatorial $2 \times 2 \times 2$, que gera 8 tratamentos, para os quais foram feitas seis repetições com 250 sementes cada uma.

Para avaliar a acurácia na deposição de sementes nos ensaios de laboratório, a distância referência entre sementes (Xref) citada em ABNT (1994) foi substituída pelo tempo referência (Tref), que corresponde ao intervalo de tempo teórico entre a passagem de duas células consecutivas do mecanismo dosador sobre o ponto de ejeção; portanto, para uma velocidade tangencial de $0,10 \mathrm{~m} \mathrm{~s}^{-1}$, Tref $=0,106 \mathrm{~s}$. Considerando-se as medidas de precisão de semeadura apresentadas em ABNT (1994), os tempos aceitáveis ficam compreendidos entre $0,053 \mathrm{~s}$ e $0,159 \mathrm{~s}$, os falhos acima de $0,159 \mathrm{~s}$ e os múltiplos abaixo de $0,053 \mathrm{~s}$; na velocidade tangencial de $0,25 \mathrm{~m} \mathrm{~s}^{-1}$, Tref $=0,044 \mathrm{~s}$; então, os tempos aceitáveis ficam compreendidos entre $0,022 \mathrm{~s}$ e $0,066 \mathrm{~s}$, os falhos acima de $0,066 \mathrm{~s}$ e os tempos múltiplos abaixo de $0,022 \mathrm{~s}$.

Os tempos referência foram medidos com um sensor de sementes de fibras óticas, descrito por Martins et al. (2003), disponível na bancada de ensaios e posicionado na saída do tubo condutor. $\mathrm{O}$ sensor media o tempo decorrido entre a passagem de duas sementes consecutivas, sendo o sinal analógico gerado pelo receptor convertido para digital com resolução de 10 bits, a uma taxa de amostragem de $50 \mathrm{kHz}$.

Nos ensaios se utilizaram sementes básicas de arroz da cultivar BRS 7, com 100,0\% de pureza, umidade de 13,0\% bu e $96,0 \%$ de germinação. Obtiveram-se as dimensões e a massa das sementes por meio de medições diretas de amostras retiradas do lote disponível; para tanto, foram medidos, com o auxílio de um micrômetro, o comprimento, a largura e a espessura de dez amostras de dez sementes cada uma; também foi medida, em balança analítica, a massa de três amostras de cem sementes cada uma.

Os danos mecânicos existentes nas sementes (grãos quebrados, grãos descascados, grão fissurados) foram avaliados visualmente e as sementes colocadas sobre uma lâmina de vidro, embaixo da qual se ligava uma lâmpada incandescente 
de $40 \mathrm{~W}$, cujo procedimento torna as sementes translúcidas, permitindo a identificação de qualquer danificação mecânica. Utilizaram-se, para este fim, dez amostras de cem sementes, em que o resultado dessas determinações é apresentado na Tabela 1. Os danos mecânicos provocados nas sementes durante o processo de dosagem e de deposição foram avaliados da mesma forma, com base em amostras retiradas na saída do tubo condutor para cada um dos tratamentos em questão.

Tabela 1. Características físicas das sementes de arroz da cultivar BRS 7 utilizadas

\begin{tabular}{lcccr}
\hline Parâmetro & Média & $\begin{array}{c}\text { Intervalo } \\
\text { de confiança } \\
\boldsymbol{\alpha}=\mathbf{0 , 0 5}\end{array}$ & $\begin{array}{c}\text { Desvio } \\
\text { padrão }\end{array}$ & CV (\%) \\
Comprimento (mm) & 9,44 & 0,10 & 0,49 & 5,17 \\
Largura (mm) & 2,40 & 0,02 & 0,11 & 4,57 \\
Espessura (mm) & 2,00 & 0,02 & 0,10 & 4,84 \\
Dano mecânico (\%) & 0,80 & 0,64 & 1,03 & 129,13 \\
Massa de 1.000 & 25,87 & 0,48 & 0,42 & 1,64 \\
sementes (g) & & & & \\
\hline
\end{tabular}

\section{RESULTADOS E DISCUSSÃO}

\section{Porcentagem de enchimento de células}

Apresentam-se, na Tabela 2, as médias da porcentagem de enchimento de células dos tratamentos e a sua comparação estatística. A análise de variância dos dados mostrou que não há interação entre os fatores, ou seja, os efeitos da velocidade sobre a porcentagem de enchimento de células não dependem da posição da escova e vice-versa; os fatores podem, portanto, ser tratados isoladamente. Nota-se, através da comparação das médias apresentadas na Tabela 2, que a porcentagem de enchimento de células é menor na posição 2 das escovas, mas os valores se encontram mais próximos de $100 \%$, indicando uma ocorrência menor de dosagens múltiplas. O aumento da velocidade tangencial reduziu a porcentagem de enchimento das células do cilindro e na maior velocidade, o enchimento das células está mais próximo de $100 \%$ e é menor que o obtido com a velocidade de $0,10 \mathrm{~m} \mathrm{~s}^{-1}$.

A porcentagem de enchimento de células foi alta quando a escova estava na posição mais próxima ao fundo da câmara de dosagem. Acredita-se que, nesta situação, a ponta da escova, que tem a finalidade de atuar como exclusor de sementes extras, não esteja sendo suficiente para remover o grande número de sementes presentes. $\mathrm{O}$ aumento do comprimento das cerdas na ponta da escova, ou a criação da possibilidade de variar localmente a pressão da escova sobre o cilindro, pode tornar a exclusão de sementes extras, mais eficiente; quando a escova se encontra mais afastada do fundo da câmara de dosagem, a porcentagem de enchimento de células diminui, pois a ação da força da gravidade, atuando sobre as sementes, auxilia o funcionamento da escova, fazendo com que parte delas seja desalojada das células do cilindro e voltem para a câmara de dosagem.

A redução da porcentagem de enchimento de células com
Tabela 2. Médias das porcentagens de enchimento de células do cilindro e seu coeficiente de variação (CV) em função da velocidade tangencial e da posição das escovas

\begin{tabular}{ccrcrc}
\hline $\begin{array}{c}\text { Velocidade } \\
\text { tangencial }\left(\mathbf{m ~ s}^{-1}\right)\end{array}$ & $\begin{array}{c}\text { Posiçãol } \\
(\%)\end{array}$ & $\begin{array}{c}\text { CV } \\
(\%)\end{array}$ & $\begin{array}{c}\text { Posição 2 } \\
(\%)\end{array}$ & $\begin{array}{c}\text { CV } \\
(\%)\end{array}$ & $\begin{array}{c}\text { Média das } \\
\text { velocidades }\end{array}$ \\
0,10 & 181,9 & 16,6 & 103,5 & 17,2 & $142,7 \mathrm{~A}$ \\
0,22 & 152,0 & 7,8 & 113,3 & 3,7 & $132,7 \mathrm{AB}$ \\
0,30 & 143,0 & 7,4 & 76,6 & 11,4 & $109,8 \mathrm{~B}$ \\
\hline Média das posições & $159,0 \mathrm{a}$ & & $97,8 \mathrm{~b}$ & & \\
\hline
\end{tabular}

Médias seguidas da mesma letra não diferem estatisticamente a nível de significância de $5 \%$ pelo teste $\mathrm{t}$

o aumento da rotação do cilindro era esperada; esta característica denota o menor tempo disponível para as sementes se alojarem nas células do cilindro.

\section{Regularidade de distribuição longitudinal de sementes}

Apresentam-se, na Tabela 3, os resultados médios de cada tratamento considerado. Embora a análise de variância tenha apontado para o efeito conjunto da velocidade tangencial das células e da inclinação lateral do protótipo sobre a porcentagem de tempos aceitáveis, o desdobramento da análise e a comparação das médias dentro de cada nível desses fatores, através de um teste $\mathrm{t}$, demonstraram que não há diferença estatística entre elas no nível de significância de 5\%. Como se verificou também que as médias dos tempos aceitáveis não diferem em função das variáveis independentes consideradas separadamente constatou-se que a variação desses três fatores, dentro dos níveis considerados, não afeta os tempos aceitáveis entre sementes do protótipo. A média geral dos tempos aceitáveis no experimento foi de $34,5 \%$, sendo que a média mais alta, $38,2 \%$, aconteceu com o protótipo nivelado, na maior velocidade e com o maior nível de sementes; já a menor média, $31,9 \%$, ocorreu com o protótipo inclinado, na maior velocidade e com o menor nível de sementes no reservatório.

Tabela 3. Porcentagens médias dos tempos referência entre sementes obtidas com o protótipo em cada classe de distribuição (Falhos, F; Aceitáveis, A; Múltiplos, M), em função da inclinação lateral, da velocidade tangencial das células e do nível de

\begin{tabular}{|c|c|c|c|c|c|c|c|}
\hline \multirow{3}{*}{\multicolumn{2}{|c|}{$\begin{array}{l}\text { Velocidade Inclinação } \\
\left(\mathrm{m} \mathrm{s}^{-1}\right)\end{array}$}} & \multicolumn{6}{|c|}{ Nível do reservatório (\%) } \\
\hline & & \multicolumn{3}{|c|}{25} & \multicolumn{3}{|l|}{50} \\
\hline & & $\mathrm{F}^{*}$ & A & $M$ & $\mathbf{F}$ & A & $M$ \\
\hline \multirow{2}{*}{0,10} & 0 & 13,3 & 35,2 & 51,5 & 12,2 & 33,7 & 54,1 \\
\hline & 11 & 23,2 & 32,7 & 44,0 & 26,0 & 33,0 & 41,0 \\
\hline \multirow{2}{*}{0,25} & 0 & 22,6 & 37,9 & 39,5 & 31,4 & 38,2 & 30,4 \\
\hline & 11 & 45,4 & 31,9 & 22,6 & 38,2 & 33,7 & 28,1 \\
\hline
\end{tabular}

* F - falhos; A - aceitáveis; M - múltiplos

A análise de variância da porcentagem de tempos falhos mostrou o efeito significativo das variações dos níveis da velocidade e da inclinação lateral, individualmente, sobre os resultados; observou-se, também, a interação dos três fatores, razão pela qual foi feita a comparação conjunta das médias dos tratamentos de duas em duas, através do teste de Duncan com nível de significância de 5\%. As menores porcentagens de tempos falhos ocorrem na menor velocidade 
com o dosador nivelado, independentemente do nível de sementes; já os maiores valores ocorrem na velocidade de $0,25 \mathrm{~m} \mathrm{~s}^{-1}$, com inclinação de $11^{\circ}$ e nível baixo de sementes no reservatório, que é significativamente maior que o observado para as mesmas condições, porém com mais sementes no reservatório. $\mathrm{O}$ efeito negativo do aumento da velocidade também se dá com o dosador nivelado e no nível baixo de sementes, quando a porcentagem de falhos passa de 13,3 para $22,6 \%$ e com o dosador inclinado e com nível alto de sementes, quando passa de 26,0 para $38,2 \%$; de maneira geral, prevalecem os efeitos individuais da velocidade e da inclinação sobre a porcentagem de tempos falhos. Em ambos os casos o efeito é inversamente proporcional à alteração nos níveis desses fatores. O nível de sementes foi importante na maior velocidade com o dosador inclinado lateralmente.

A análise de variância das médias das porcentagens dos tempos múltiplos, também apresentou interação significativa no nível de 5\%, entre os três fatores estudados; da mesma forma, a velocidade tangencial e a inclinação lateral foram os fatores individuais que mais influenciaram nessa variável de resposta. A análise conjunta dos três fatores através da comparação pelo teste de Duncan com nível de significância de 5\%, mostram, como era de se esperar, que a porcentagem de tempos múltiplos é menor na maior velocidade de $0,25 \mathrm{~m} \mathrm{~s}^{-1}$, independentemente da inclinação e do nível de sementes; a exceção ocorre com o dosador nivelado e com o nível baixo de sementes, que apresentou maior valor igualando-se aos valores obtidos na menor velocidade e com o dosador inclinado com qualquer um dos níveis de sementes. Obtiveram-se as maiores porcentagens de tempos múltiplos na menor velocidade, em que a variação do nível de sementes no reservatório não teve efeito significativo nos resultados para uma mesma inclinação; também, na menor velocidade a inclinação teve influência apenas na variável de resposta no maior nível de sementes no reservatório, o que pode indicar que, com o nível de $50 \%$, pode estar havendo dificuldade de entrada de sementes na câmara de dosagem quando se dá a inclinação do conjunto.

O estudo da influência da velocidade tangencial das células do cilindro, da inclinação lateral do protótipo e do nível de sementes sobre a regularidade de distribuição longitudinal de sementes, mostrou que esses fatores não alteram os tempos aceitáveis entre sementes; se, por um lado, isto é bom, demostrando que o protótipo tem condições de se adaptar a várias situações, por outro o valor médio obtido foi de apenas $34,5 \%$, o qual está abaixo da meta estabelecida para este requisito de projeto; atribui-se este baixo valor à falta de ajuste da geometria das células individualizadoras (profundidade, largura, comprimento do chanfro de entrada e excentricidade) com as características das escovas (comprimento, diâmetro e densidade das cerdas). O emprego de células com outras características geométricas, aliadas a outras configurações de escovas, pode apresentar um desempenho melhor nessa métrica, pois se forem somados os tempos aceitáveis com os tempos múltiplos médios já obtidos, chegarse-á a um valor de 72,4\% (na melhor repetição, obteve-se uma soma de $86,7 \%$ ); acredita-se, então, que há potencial para melhoria da acurácia desse protótipo.
A porcentagem de tempos aceitáveis observados na saída do tubo condutor não atendeu a critérios de qualidade na regularidade de distribuição das sementes, razão por que, para que isto fosse possível, a porcentagem de tempos aceitáveis e, conseqüentemente, a de espaçamentos aceitáveis entre sementes no sulco, deveriam ser superiores a $60 \%$ (Coelho, 1996), no entanto, deve-se levar em consideração que o valor apontado pelo autor se refere a sementes graúdas para as quais a pesquisa já vem estudando as dependências entre uniformidade de distribuição longitudinal de sementes e produtividade. Para as sementes miúdas não se tem conhecimento do nível de acurácia necessário para se obter o melhor aproveitamento do potencial genético das sementes com vista a produção; logo, a obtenção de $34,5 \%$, em média, de tempos aceitáveis, com o protótipo, não chega a ser um resultado desanimador, especialmente se tendo em vista as dificuldades inerentes à semeadura de precisão de sementes miúdas.

Os tempos falhos e múltiplos sofreram influências semelhantes da velocidade, da inclinação e, em menor grau, do nível de sementes no reservatório. De forma geral, o aumento de velocidade reduziu a porcentagem de tempos múltiplos, independentemente da inclinação lateral e do nível de sementes mas aumentou a porcentagem de tempos falhos; esta característica está relacionada ao menor tempo disponível para as sementes entrarem nas células quando a velocidade é maior.

A inclinação lateral teve maior influência sobre a ocorrência de tempos falhos. No geral, a porcentagem de tempos falhos é maior quando o protótipo está inclinado em $11^{\circ}$; percebe-se, então, que na presença de inclinação existe maior dificuldade de individualização da semente, pois a atuação da força da gravidade tende a afastar a semente da célula, o que poderia ser compensado pela adoção de uma célula cuja geometria favorecesse a retenção das sementes nesta situação.

O nível de sementes no reservatório teve pouca influência nos resultados (a mais notória ocorreu no aumento dos tempos falhos, na maior velocidade, quando o nível foi reduzido para $25 \%$ ), indicando que a quantidade de sementes que chega à câmara de dosagem é adequada para o funcionamento do protótipo nas condições ensaiadas.

\section{Danificação de sementes}

As amostras recolhidas na saída do tubo condutor para a quantificação do enchimento das células do cilindro mecânico foram utilizadas para a obtenção dos danos mecânicos nas sementes. A análise de variância dos dados comprovou não haver interação entre a velocidade tangencial das células e a posição das escovas na danificação de sementes; assim, pode-se estudar os efeitos dos fatores, individualmente. Na posição 1 , os danos mecânicos médios às sementes foram de $4,2 \%$ enquanto na posição 2 atingiram $2,7 \%$, porém não há diferença estatística entre elas, a nível de significância de 5\%, pelo teste t. O aumento de velocidade reduziu o nível médio de danos às sementes; nas velocidades tangenciais de 0,$10 ; 0,22$ e $0,30 \mathrm{~m} \mathrm{~s}^{-1}$, os danos médios foram de 4,2; 3,3 e 2,9\%, respectivamente. O teste t, com nível de significância de 5\%, mostrou que apenas os danos da maior e da menor velocidade podem ser considerados diferentes. 
A média geral de danos mecânicos causados às sementes pelo protótipo de cilindro mecânico, foi de 3,5\%. A comparação entre a danificação mecânica desse experimento e a danificação já presente no lote de sementes utilizado nos testes $(0,8 \%$ - Tabela 1$)$, feita através de uma análise de variância, rejeita a hipótese, com 5\% de significância, de que os danos mecânicos podem ser considerados iguais, indicando que este protótipo ocasiona danificação mecânica adicional às sementes de arroz.

Verificou-se que a danificação mecânica foi inversamente proporcional à velocidade tangencial das células do cilindro; também foi inversamente proporcional à velocidade tangencial, a porcentagem de enchimento de células; nota-se, portanto, que o excesso de sementes nas células é um dos fatores responsáveis pelos danos mecânicos. Com um número maior de sementes nas células, algumas delas ficam mais expostas à ação das cerdas das escovas, aumentando as chances de danificação e, desta forma, a solução do problema da baixa acurácia na dosagem de sementes pode contribuir, mesmo indiretamente, para a redução dos danos mecânicos.

\section{CONCLUSÕES}

1. Os resultados obtidos nos diversos ensaios do protótipo na dosagem e deposição de sementes de arroz indicaram que a porcentagem de enchimento das células do cilindro vertical estreito foi, em média, superior a $100 \%$ para velocidades tangenciais das células de até $0,30 \mathrm{~m} \mathrm{~s}^{-1}(25,8 \mathrm{rpm})$.

2. Com o melhor ajuste na posição das escovas de transporte, esses valores foram de $103,5 \%$ na velocidade de $0,10 \mathrm{~m} \mathrm{~s}^{-1}(8,8 \mathrm{rpm})$ e de $113,3 \%$ na velocidade de $0,22 \mathrm{~m} \mathrm{~s}^{-1}$ (18,6 rpm).

3. A regularidade de distribuição longitudinal de sementes alcançada na saída do tubo condutor, expressa através dos tempos aceitáveis, foi de $34,5 \%$ abaixo, portanto, da meta estabelecida para este requisito de projeto (75\% de aceitáveis).

4. Tanto o nível de sementes no reservatório quanto a inclinação lateral, não afetaram, de forma significativa, a acurácia alcançada.

5. O protótipo causou danificação mecânica às sementes de arroz $(3,5 \%)$ significativamente maior que os danos preexistentes nas amostras.
6. Os danos mecânicos às sementes foram inversamente proporcionais à velocidade tangencial das células, dentro da faixa estudada.

\section{AGRADECIMENTOS}

À FINEP - Financiadora de Estudos e Projetos que, através do programa RECOPE na Rede de Engenharia Agroindustrial de Alimentos, financiou a construção da instrumentação de testes e do protótipo utilizado neste trabalho.

\section{LITERATURA CITADA}

ABNT - Associação Brasileira de Normas Técnicas. Projeto de norma 04:015:06-004 - Semeadora de precisão: Ensaio de laboratório. S. Paulo: ABNT, 1994. 22p.

Butierres, E. Desempenho do mecanismo dosador pneumático a vácuo para arroz. Pelotas: UFPEL, 2003. 61p. Tese Doutorado

Casão Júnior, R. Desenvolvimento de sistema pneumático de dosagem e transporte de sementes. Campinas: UNICAMP, 1996. 191p. Tese Doutorado

Coelho, J. L. D. Ensaio e certificação das máquinas para a semeadura. In: Mialhe, L. G. Máquinas agrícolas: Ensaios e certificação. São Paulo: Fundação de Estudos Agrários Luiz de Queiroz, 1996. cap. 11, p551-571.

Fey, E.; Justino, A.; Weirich Neto, P. H.; Santos, S. R. Efeito da velocidade tangencial do mecanismo dosador tipo disco perfurado horizontal na distribuição de sementes de feijão ( $P h a-$ seolus vulgaris). In: Congresso Brasileiro de Engenharia Agrícola, 28, 1999, Pelotas. Anais ... Jaboticabal: SBEA, 1999. CD Rom

Kachman, S. D.; Smith, J. A. Alternative measures of accuracy in plant spacing for planters using single seed metering. Transactions of the ASAE, v.38, n.2, p.379-387, 1995.

Martins, C. F.; Costa, R. L.; Franzen, T. A.; Reis, A. V. Aplicação de um filtro digital implementado em microcontrolador para sensoreamento óptico. Controle e instrumentação, v.8, n.87, p.50-55, 2003.

Reis, A. V.; Forcellini, F. A. Functional analysis in the evaluation of four concepts of planters. Ciência Rural, v.32, n.6, p.969-75, 2002. 